\title{
FURTHER OBSERVATIONS ON LUTZOMYIA UBIQUITALIS (PSYCHODIDAE: PHLEBOTOMINAE), THE SANDFLY VECTOR OF LEISHMANIA NIANNIA) LAINSONI
}

\author{
RALPH LAINSON; JEFFREY J. SHAW; ADELSON A. A. SOUZA; \\ FERNANDO T. SILVEIRA \& ALOISIO FALQUETO*
}

\begin{abstract}
Seção de Parasitologia, Instituto Evandro Chagas, Caixa Postal 3, 66017-970 Belém, PA, Brasil *Centro Biomédico da Universidade Federal do Espirito Santo, Caixa Postal 780, 29060-900 Vitória, ES, Brasil
\end{abstract}

Leishmania (Viannia) lainsoni was first isolated and described from cases of cutaneous leishmaniasis in Pará state, Amazonian Brazil (F. T. Silveira et al., 1987, Mem. Inst. Oswaldo Cruz, 82: 289-292). Human infection appears to be uncommon, however, compared with that caused by $L .(V$.$) braziliensis, L. (V.)$ guyanensis, other incompletely identified parasites of the braziliensis and guyanensis complexes, or by Leishmania (Leishmania) amazonensis (F. T. Silveira et al., 1991, Trans. R. Soc. Trop. Med. Hyg., 85: 735-738).

Following the examination of many different species of wild animals from the forests of Pará, isolation of $L$. (V.) lainsoni was limited to seven specimens of Agouti paca (Rodentia: Dasyproctidae), from areas near Tucuruí, leading us to suggest this animal as a major reservoir host of the parasite (F. T. Silveira et al., 1991, Rev. Inst. Med. Trop. São Paulo, 33: 18-22).

In the same year (F. T. Silveira et al., 1991, Mem. Inst. Oswaldo Cruz, 86: 127-130) our studies were concentrated on attempts to indicate the phlebotomine vector of $L$. (V.) lainsoni. Working in two similar areas of primary forest, in one of which a patient had frequently been hunting, we captured and examined sandflies of ten different species and isolated $L$. (V.) lainsoni from eight heavily infected Lutzomyia ubiquitalis (Mangabeira): no other sandfly species was found infected with the parasite. In addition, the re-examination of a Leishmania isolate previously made from $L u$. ubiquitalis in the foothills of the Serra dos Carajás, Pará, in 1983, showed that this, too, was $L$. (V.) lainsoni. The isolate had been provisionally designated as ". . . an unnamed parasite of the subgenus Viannia". (R. Lainson

Received 4 May 1992.

Accepted 24 June 1992.
\& J. J. Shaw, 1987, p. 100. In W. Peters \& R. Killick-Kendrick (eds) The Leishmaniases in Biology and Medicine Vol. I, Academic Press, London).

Superficially, these findings strongly indicated $L u$. ubiquitalis as the vector of $L$. $(V$.) lainsoni, and they were supported by our observation that large numbers of this fly, caught in nearby forest and then maintained in the laboratory for $48 \mathrm{~h}$, readily fed on the arm of a volunteer. The enigma remained, however, that on no occasion during our many field studies in Amazonia had we taken $L u$. ubiquitalis from human bait in the forest. We could only conclude that ". . . under certain conditions it will bite man, and transmit the parasite to him", and that ". . . This is in keeping with the relatively rare occurence of human infection".

New observations - In June 1991 we visited our study area ("N2") in the Serra dos Carajás, Pará (R. D. Ward et al., 1973, Trans. R. Soc. trop. Med. Hyg., 67: 174-183). Our express intention was to obtain specimens of Psychodopygus wellcomei infected with $L$. $(V$.) braziliensis, for studies on the use of specific DNA probes in the identification of both the vector and the parasite (P. D. Ready et al., 1991, Mem. Inst. Oswaldo Cruz, 86: 41-49). We also hoped, however, to obtain further information on the behaviour of $L u$. ubiquitalis.

Trapping methods, for five consecutive nights, were as previously described (L. Ryan et al., 1986, p. 307-320. In Instituto Evandro Chagas: 50 anos de contribuição às ciências biológicas e à medicina tropical. Vol. I. Min. Saúde, F. SESP, Belém, Pará, Brasil), and as follows: (a) Two unbaited CDC miniature lighttraps, set at about $1.0 \mathrm{~m}$ above the forest floor. (b) A CDC trap suspended over a caged chicken, at the same height. (c) An unbaited CDC trap in the forest canopy, at about 15-20 
m. (d) A disney-trap, baited with a hamster, at ground level. All these traps were in operation from 18.00-07.00 h. (e) A Shannon-trap, illuminated by a ground-level fluorescent striplight, in use from 19.00-20.00, each night. (f) Human bait: two men aspirating feeding flies from their arms, between the hours 19.00-20.00, each night.
The results are summarized in Table. Only female sandflies are recorded, and all were dissected for evidence of intestinal flagellates. Methods for the blood-agar culture of material from positive sandflies and for the identification of isolations were as previously described (F. T. Silveira et al., 1991, Mem. Inst. Oswaldo Cruz, 86: 127-130).

TABLE

Presence of Leishmania in some female sandflies (Psychodidae: Phlebotominae) taken by a variety of trapping methods in Serra dos Carajás, Pará, Brazil : 15-19 June, 1991

\begin{tabular}{|c|c|c|c|c|c|c|c|c|}
\hline Sandfly species & $\begin{array}{c}\text { CDC } \\
\text { (ground) } \\
\text { no bait }\end{array}$ & $\begin{array}{l}\text { CDC } \\
\text { (ground) } \\
\text { chicken }\end{array}$ & $\begin{array}{c}\text { CDC } \\
\text { (canopy) } \\
\text { no bait }\end{array}$ & $\begin{array}{c}\text { Shannon } \\
\text { trap }\end{array}$ & $\begin{array}{c}\text { Disney } \\
\text { trap }\end{array}$ & $\underset{\text { bait }}{\text { Human }}$ & $\begin{array}{l}\text { Infected } \\
\text { flies }\end{array}$ & $\begin{array}{c}\text { Parasite } \\
\text { (isolations) }\end{array}$ \\
\hline Lutzomyia aragaoi & 1 & - & - & - & - & - & - & 1 \\
\hline Lu, brachyphalla & 1 & - & - & - & 2 & - & - & 3 \\
\hline Lu. carvalhoi & 1 & 1 & - & 1 & - & - & - & 3 \\
\hline Lu, damascenoi & 3 & - & - & - & 1 & - & - & 4 \\
\hline Lu. dasypodogeton & 1 & 1 & - & - & - & - & - & 2 \\
\hline Lu. dendrophila & 1 & - & - & - & - & - & - & 1 \\
\hline Lu. flaviscutellata & 3 & - & - & - & 12 & - & - & 15 \\
\hline Lu. furcata & 1 & - & - & _- & - & - & - & 1 \\
\hline Lu. saulensis & - & - & - & - & 3 & - & - & 3 \\
\hline Lu. shawi & 1 & - & 2 & 4 & - & 1 & - & 8 \\
\hline Lu. tuberculata & 7 & 2 & 1 & - & - & 1 & - & 11 \\
\hline Lu. ubiquitalis & 142 & 3 & 21 & 30 & - & 1 & 4 & L. (V.) lainsoni (3) 197 \\
\hline Lu. umbratilis & 41 & 2 & 20 & - & - & 1 & - & 64 \\
\hline $\begin{array}{l}\text { Lu. whitmani } \\
\text { Psychodopvgus }\end{array}$ & 1 & - & - & - & - & - & - & 1 \\
\hline amazonensis & - & - & - & 2 & - & - & - & 2 \\
\hline Ps. carrerai & 2 & 3 & 1 & 24 & - & 9 & - & 39 \\
\hline Ps. davisi & 6 & 2 & - & 6 & - & 4 & - & 18 \\
\hline Ps. hirsutus & - & - & - & 2 & - & - & - & 2 \\
\hline Ps. paraensis & - & - & - & 9 & - & 3 & - & 12 \\
\hline Ps. wellcomeil & & & & & & & & \\
\hline complexus & 12 & 5 & 1 & 431 & 1 & 221 & $1^{a}$ & L. (V.) braziliensis (1) 671 \\
\hline Total & 224 & 19 & 26 & 529 & 19 & 241 & 5 & 1058 \\
\hline
\end{tabular}

$a$ : females of Ps. wellcomei and Ps. complexus are morphologically indistinguishable: the infected sandfly was identified as $P$ s. wellcomei by a specific DNA probe (Dr P. D. Ready, pers. comm.)

Recognition and separation of $L u . u b i$ quitalis in mixed catches is relatively easy due to this insect's large size and uniform dark colour. About 80 were accumulated in a cage and, at a time varying from $24-48 \mathrm{~h}$ after capture, offered a bloodmeal from the arm of a volunteer. A total of 64 engorged, and were returned to Belém to establish a laboratory colony.

Subsequent dissection of the experimentally fed flies showed one of them to be heavily infected. Although two bite-reactions on the hand of the volunteer persisted for several days after the others had faded, no parasites could be detected in Giemsa-stained smears of exudate from them, and blood-agar culture was not attempted. As the man had previously been infected with other parasites of the subgenus Viannia, his failure to produce a lesion due to $L$. $(V$.) lainsoni was not unduly surprising.

In conclusion, although only a single specimen of Lu. ubiquitalis was caught feeding on man in its natural environment, this does greatly strengthen our belief that this sandfly is a vector of $L$. (V.) lainsoni to man, as does the finding of four more naturally infected specimens of this sandfly. In this respect one must take into account the liklihood that if a casual visitor 
spending a total of only $5 \mathrm{~h}$ in the forest is bitten by one $L u$. ubiquitalis, those who regularly work or hunt there will be bitten by very many more. Further support for this view comes from our consistent failure to find $L$. (V.) lainsoni in any other sandfly species in the enzootic areas studied; the repeated demonstration that $\mathrm{Lu}$. ubiquitalis is 'triggered' into avidly attacking man under unusual conditions; and the fact that this sandfly was the second most abundant species captured in the present study.

This interesting eco-epidemiology is not without parallel. Another Amazonian parasite, $L$. (V.) shawi, was first described in monkeys, sloths and procyonids: among the many sandfly species examined it has been isolated, on six occasions, only from $\mathrm{Lu}$. whitmani - a fly we have so far failed to catch from human bait in
Amazonian forest (R. Lainson et al., 1989, Ann. Parasit. Hum. Comp., 64: 200-207). Recently, however, $L$. (V.) shawi has been recorded in man (J. J. Shaw et al., 1991, Ann. Parasit. Hum. Comp., 66, 243-246). This anomalous situation can have but one of two explanations: either there is an alternative, anthropophilic vector that we have so far not detected or, like Lu. ubiquitalis, Amazonian Lu. whitmani does bite man under certain circumstances.

Acknowledgements: to The Wellcome Trust, London and the Instituto Evandro Chagas, F. N. S., under whose auspices this work was carried out; to the Companhia Vale do Rio Doce who provided excellent facilities for this research; and to Deocleciano G. Primo, Iorlando da Rocha Barata and José Paulo N. Cruz for technical help. 